\title{
The right stuff? Imaging cardiac sympathetic neuronal integrity of the right ventricle in pulmonary arterial hypertension
}

\author{
James T. Thackeray, $\mathrm{PhD}^{\mathrm{a}}$ \\ a Department of Nuclear Medicine, Hannover Medical School, Hannover, Germany
}

Received Jun 24, 2020; accepted Jun 24, 2020

doi: $10.1007 / \mathrm{s} 12350-020-02495-5$

\section{See related article, pp. 407-422}

Altered sympathetic neuronal signaling is a hallmark of the failing heart, initially as a compensatory mechanism, but chronic stimulation exacerbates damage and promotes progressive functional decline. Global and regional changes in sympathetic nerve density may be non-invasively interrogated by radiolabeled analogs of endogenous neurotransmitters, providing insight into the presynaptic cycling of norepinephrine, including neuronal reuptake, vesicular packaging, as well as active and passive release. ${ }^{1}$ Imaging of the intrinsic cardiac sympathetic neuronal signaling system has posed numerous challenges, particularly relating to the quantification of innervation relative to sympathetic activity. While large-scale imaging studies have emphasized the relationship between reduced sympathetic neuronal signal and heart failure progression, ${ }^{2}$ or heterogeneous innervation and sudden cardiac arrest, ${ }^{3}$ routine clinical application of sympathetic neuronal imaging has remained elusive.

The direct involvement of the sympathetic nervous system in pulmonary arterial hypertension (PAH) has garnered interest in recent years. ${ }^{4}$ Noninvasive evaluation of sympathetic neuronal contribution in PAH could provide mechanistic insights into disease pathogenesis

Editorial on: Zelt et al [11C]meta-hydroxyephedrine PET Evaluation in Experimental Pulmonary Arterial Hypertension: Effects of Carvedilol of Right Ventricular Function and Sympathetic Activity

Reprint requests: James T. Thackeray, PhD, Department of Nuclear Medicine, Hannover Medical School, Carl Neuberg Str 1, D30625

Hannover, Germany; Thackeray.James@mh-hannover.de

J Nucl Cardiol 2021;28:423-6.

$1071-3581 / \$ 34.00$

Copyright (c) 2021 American Society of Nuclear Cardiology. and targeted therapy. Imaging, however, has been generally restricted to interrogating the left ventricle by necessity, owing to the limited ability to resolve the thinner and less densely innervated right ventricle. In this issue of the Journal of Nuclear Cardiology, Zelt and colleagues use ${ }^{11} \mathrm{C}$-meta-hydroxyephedrine (HED) imaging to investigate cardiac sympathetic neuronal integrity in the left and right ventricle of a rat model of PAH with and without pharmacologic inhibition of adrenergic signaling via the third-generation betaadrenoceptor blocker carvedilol. ${ }^{5}$

The PAH model induced by the vascular endothelial growth factor receptor protein tyrosine kinase $1 / 2$ inhibitor, Sugen 5416, in combination with prolonged hypoxia exposure generates marked right ventricular hypertrophy and severe PAH. ${ }^{6}$ In the current investigation, Zelt et al assess left and right ventricular ${ }^{11} \mathrm{C}$-HED retention at 9 weeks after Sugen-induced PAH and 4 weeks of continuous carvedilol or vehicle treatment. They observe limited differences in the hemodynamics and right ventricle function in response to beta-blocker therapy, in parallel with no difference in the ${ }^{11} \mathrm{C}-\mathrm{HED}$ distribution volume and modestly reduced tracer washout from the right ventricle..$^{5}$ Notably, the retention of ${ }^{11} \mathrm{C}$-HED in the right ventricle correlated directly with dopamine-beta-hydroylase-positive sympathetic neurons and inversely with right ventricle pressure. The expansion of ${ }^{11} \mathrm{C}$-HED imaging methods to the right ventricle is a significant achievement, which may build a new foundation for further applications of sympathetic neuronal imaging. The clinical relevance of these findings, combined with the inherent challenge of quantitative cardiac sympathetic neuronal imaging, proffer an opportunity for further study, and necessitate careful investigation.

One limitation is the lack of a demonstrable response to the carvedilol treatment. Previous studies in PAH rats have reported a moderate reduction in heart rate, indicative of suppressed cardiac sympathetic 
activity, ${ }^{7}$ which, while possibly present, is more subtle in the present report. It is relevant that the treated PAH animals do not exhibit differences in the right ventricle geometry nor pressure compared to vehicle-treated control group. To effectively demonstrate the sensitivity of ${ }^{11} \mathrm{C}$-HED to detect therapeutic response necessitates clearer delineation of the therapeutic efficacy. In a small clinical study of idiopathic PAH patients, titrated bisoprolol lowered heart rate, but ${ }^{11} \mathrm{C}$-HED signal remained equivalent to baseline pre-treatment measurements, and right ventricle contractile function did not improve. ${ }^{8}$ Such observations raise questions as to the efficacy of beta-blocker therapy for PAH and more critical questions as to the accuracy of ${ }^{11} \mathrm{C}-\mathrm{HED}$ retention measurements. The impact of beta-blockers on heart rate and on ${ }^{11} \mathrm{C}$-HED retention and washout cannot be considered mutually exclusive. Retention of ${ }^{11} \mathrm{C}$-HED is highly flow dependent, such that lower heart rate can certainly contribute to tracer uptake and washout. ${ }^{9}$

This consideration returns to the crux of the ${ }^{11} \mathrm{C}$ HED quandary. Chiefly, what does ${ }^{11} \mathrm{C}-\mathrm{HED}$ actually quantify? Studies in small and large animal models have established distinct differences in quantitative retention and regional distribution of various radiolabelled norepinephrine analogs, depending on affinity for presynaptic uptake-1 and vesicular monoamine transporter, and susceptibility to monoamine oxidase. ${ }^{10}$ Moreover, the precise relationship between ${ }^{11} \mathrm{C}-\mathrm{HED}$ and sympathetic activity remains equivocal. While higher norepinephrine content leads to reduced ${ }^{11} \mathrm{C}$ HED uptake, ${ }^{11}$ and cardiac uptake-1 expression correlates inversely with ${ }^{11} \mathrm{C}$-HED retention. ${ }^{12}$ These observations suggest a relationship to sympathetic neuronal activity, they need to be backed up with definitive experimental evidence, rather than preconceived solutions. The value of retention index remains contentious, especially considering the cyclic nature of uptake and release of norepinephrine analogs. The PAREPET study concludes that the relative area of denervation more powerfully predicts sudden cardiac arrest than the absolute retention index values. ${ }^{13}$ Subanalyses of the ADMIRE trial have suggested that patients with intermediate heart-to-mediastinal ratios, i.e., the relative global accumulation of 123-metaiodobenzylguanidine, rather than the lowest have the highest incidence of cardiac death. This would be consistent with the notion that regional heterogeneity contributes to the substrate of sudden cardiac death. In PAH, the contribution of heterogeneous innervation remains unknown.

Delineation of the PAH right ventricle is a major undertaking. To demonstrate a relationship between the HED retention and the density of right ventricle sympathetic nerve terminals is impressive, considering the limited size of the RV wall. Notably, the density of sympathetic neuronal varicosities is lower in the right ventricle than the left, compounding the challenge imposed by lower wall thickness. Accordingly, the 'true' retention of ${ }^{11} \mathrm{C}$-HED in the right ventricle remains equivocal. In the current issue, Zelt et al restrict analysis in healthy hearts to a single right ventricle, and then only a uniformity measurement. As has been necessary for the growth of left ventricle measurements, the reproducibility and accuracy of ${ }^{11} \mathrm{C}$-HED right ventricle measurements needs to be tested effectively against nerve density and activity. While the right ventricle ${ }^{11} \mathrm{C}$ HED distribution volume correlated with dopaminebeta-hydroxylase immunostaining of sympathetic neuronal varicosities, direct association of imaging to sympathetic nerve activity and catecholamine content could provide greater evidence of the validity of the imaging measurement.

Imaging in PAH has largely focused on metabolic measurements, where changes in the standardized uptake value accumulation of fatty acid substrate FTHA or glucose analog ${ }^{18} \mathrm{~F}-\mathrm{FDG}$ reflect metabolic shifts in the remodeling right ventricle. An increase in the ratio of right-to-left ventricle metabolism for FDG or FTHA inversely correlate with declining right ventricle ejection fraction. ${ }^{14}$ Indeed, the markedly increased right-to-left SUV ratio has been suggested to predict prognosis in a small study of stable patients with PAH. ${ }^{15}$ In a previous clinical study, impaired RV sympathetic innervation was identified by ${ }^{11} \mathrm{C}$-HED left heart failure patients with right ventricle dysfunction as compared to those with normal right ventricle geometry. This study utilized standardized uptake value and retention index, reporting a $\sim 20 \%$ reduction in both measurements. ${ }^{16}$ As noted, the archetypal clinical study on ${ }^{11}$ C-HED (i.e. PAREPET) denoted that the extent of the sympathetic innervation defect rather than quantitative indicators of reuptake and retention were the most powerful predictors of sudden cardiac arrest. ${ }^{13}$ This bodes well for the complicated imaging of the right ventricle, where the accuracy of quantitative assessment may be challenged by partial volume effects and lack of a standardized healthy baseline.

Growth of sympathetic neuronal imaging is impeded by current limitations, which can begin to be addressed by studies such as Zelt et al First, quantitative measurements, especially of ${ }^{11} \mathrm{C}$-HED are not uniform, and the dynamic nature of uptake and retention of lipophilic norepinephrine analogs limits the direct interpretation of the physiological meaning of altered tracer uptake. This complication is compounded by the small number of clinical sites that routinely utilize the imaging methods, which in part contributes to the lethargic growth of sympathetic neuronal imaging. The continued development, characterization, and rollout of 
fluorine-18-labeled compounds may impel broader acceptance of the measurement, and provide the impetus for standardized and reliable analysis methods that can be utilized in multiple centers, ${ }^{17,18}$ supported by expanded and validated quantification methods.

Second, cardiac molecular imaging cannot lose sight of the goal to influence clinical decision making. Earlier studies have demonstrated the sensitivity of ${ }^{11} \mathrm{C}$ HED to denote successful therapy. ${ }^{19}$ The smaller the distance between the molecular imaging probe and the therapeutic target, i.e., closer adherence to an indirect theragnostic model, the more effective the imaging agent can be. Indeed, this highlights a limitation of sympathetic neuronal imaging in its current form, that therapy tends to target the opposite side of the synapse, e.g., treating the post-synaptic adrenoceptors while imaging the presynaptic reuptake system, albeit with ancillary effects on sympathetic transmission. The widespread use and attainability of beta-blockers detracts from the value of sympathetic neuronal imaging compared to other molecular imaging targets. In nonconventional applications like PAH, such investigation of therapeutic response or non-response may have mechanistic implications for the development of alternative therapies.

Third, broader applications create more data for the validation of the imaging technique and quantification methods. In the present case, imaging of the right ventricle is an exciting new avenue to branch out cardiac sympathetic neuronal imaging from its conventional base, though direct validation of the accuracy of measurements both in disease and healthy right ventricle is needed to advance this potential.

Attaining orbit requires unified thrust in the same direction; the same principal may be applied to sympathetic neuronal imaging of the heart. A robust combination of more diverse clinical applications, greater availability of a consistent radiotracer, reliable and transferrable quantification methods, and a tangible link to therapy, together, may provide the impetus for discernible growth of sympathetic neuronal imaging in nuclear cardiology. As such, application to new conditions like PAH could contribute the 'right' stuff to fuel escape velocity from clinical stagnancy.

\section{References}

1. Thackeray JT, Bengel FM (2013) Assessment of cardiac autonomic neuronal function using PET imaging. J Nucl Cardiol 20:150-165. https://doi.org/10.1007/s12350-012-9644-4

2. Jacobson AF, Senior R, Cerqueira MD, Wong ND, Thomas GS, Lopez VA et al (2010) Myocardial iodine-123 meta-iodobenzylguanidine imaging and cardiac events in heart failure: Results of the prospective ADMIRE-HF (AdreView Myocardial Imaging for
Risk Evaluation in Heart Failure) study. J Am Coll Cardiol 55:2212-2221. https://doi.org/10.1016/j.jacc.2010.01.014

3. Boogers MJ, Borleffs CJW, Henneman MM, van Bommel RJ, van Ramshorst J, Boersma E et al (2010) Cardiac sympathetic denervation assessed with 123-iodine metaiodobenzylguanidine imaging predicts ventricular arrhythmias in implantable cardioverter-defibrillator patients. J Am Coll Cardiol 55:27692777.

4. Ciarka A, Doan V, Velez-Roa S, Naeije R, van de Borne P (2010) Prognostic significance of sympathetic nervous system activation in pulmonary arterial hypertension. Am J Respir Crit Care Med 181:1269-1275. https://doi.org/10.1164/rccm.200912-1856OC

5. Zelt JGE, Schock S, deKemp RA, Stewart DJ, Staines WA, Ahmadi A, et al. [11C]meta-Hydroxyephedrine PET Evaluation in Experimental Pulmonary Arterial Hypertension: Effects of Carvedilol on Right Ventricular Sympathetic Function. J Nucl Cardiol 2020.

6. Vitali SH, Hansmann G, Rose C, Fernandez-Gonzalez A, Scheid A, Mitsialis SA et al (2014) The Sugen 5416/hypoxia mouse model of pulmonary hypertension revisited: Long-term follow-up. Pulm Circ 4:619-629. https://doi.org/10.1086/678508

7. Bogaard HJ, Natarajan R, Mizuno S, Abbate A, Chang PJ, Chau VQ et al (2010) Adrenergic receptor blockade reverses right heart remodeling and dysfunction in pulmonary hypertensive rats. Am J Respir Crit Care Med 182:652-660. https://doi.org/10.1164/rccm. 201003-0335OC

8. Rijnierse MT, Groeneveldt JA, van Campen J, de Boer K, van der Bruggen CEE, Harms HJ et al (2020) Bisoprolol therapy does not reduce right ventricular sympathetic activity in pulmonary arterial hypertension patients. Pulm Circ 10:2045894019873548. https://d oi.org/10.1177/2045894019873548

9. Harms HJ, de Haan S, Knaapen P, Allaart CP, Rijnierse MT, Schuit RC et al (2014) Quantification of [(11)C]-meta-hydroxyephedrine uptake in human myocardium. EJNMMI Res 4:52. h ttps://doi.org/10.1186/s13550-014-0052-4

10. Lautamaki R, Sasano T, Higuchi T, Nekolla SG, Lardo AC, Holt DP et al (2015) Multiparametric molecular imaging provides mechanistic insights into sympathetic innervation impairment in the viable infarct border zone. J Nucl Med. 56:457-463. https://doi. org/10.2967/jnumed.114.149971

11. Thackeray JT, Renaud JM, Kordos M, Klein R, Dekemp RA, Beanlands RS et al (2013) Test-retest repeatability of quantitative cardiac 11C-meta-hydroxyephedrine measurements in rats by small animal positron emission tomography. Nucl Med Biol 40:676-681. https://doi.org/10.1016/j.nucmedbio.2013.03.007

12. Ungerer M, Weig HJ, Kubert S, Overbeck M, Bengel F, Schomig A et al (2000) Regional pre- and postsynaptic sympathetic system in the failing human heart-regulation of beta ARK-1. Eur J Heart Fail 2:23-31. https://doi.org/10.1016/s1388-9842(99)00072-0

13. Fallavollita JA, Heavey BM, Luisi AJ Jr, Michalek SM, Baldwa S, Mashtare TL Jr et al (2014) Regional myocardial sympathetic denervation predicts the risk of sudden cardiac arrest in ischemic cardiomyopathy. J Am Coll Cardiol 63:141-149. https://doi.org/ 10.1016/j.jacc.2013.07.096

14. Ohira H, deKemp R, Pena E, Davies RA, Stewart DJ, Chandy G et al (2016) Shifts in myocardial fatty acid and glucose metabolism in pulmonary arterial hypertension: A potential mechanism for a maladaptive right ventricular response. Eur Heart J Cardiovasc Imaging 17:1424-1431. https://doi.org/10.1093/ehjci/jev136

15. Kazimierczyk R, Szumowski P, Nekolla SG, Blaszczak P, Malek LA, Milosz-Wieczorek B et al (2020) Prognostic role of PET/MRI hybrid imaging in patients with pulmonary arterial hypertension. Heart. https://doi.org/10.1136/heartjnl-2020-316741

16. Ahmadi A, Renaud JM, Promislow S, Burwash IG, Dwivedi G, Klein $R$ et al (2020) Increased myocardial oxygen consumption 
rates are associated with maladaptive right ventricular remodeling and decreased event-free survival in heart failure patients. J Nucl Cardiol. https://doi.org/10.1007/s12350-020-02144-x

17. Werner RA, Rischpler C, Onthank D, Lapa C, Robinson S, Samnick S et al (2015) Retention kinetics of the 18F-labeled sympathetic nerve PET tracer LMI1195: Comparison with 11Chydroxyephedrine and 123I-MIBG. J Nucl Med 56:1429-1433. h ttps://doi.org/10.2967/jnumed.115.158493

18. Zelt JGE, Mielniczuk LM, Orlandi C, Robinson S, Hadizad T, Walter $O$ et al (2019) PET imaging of sympathetic innervation with [(18)F]Flurobenguan vs [(11)C]mHED in a patient with ischemic cardiomyopathy. J Nucl Cardiol 26:2151-2153. https://d oi.org/10.1007/s12350-018-01527-5

19. Hall AB, Ziadi MC, Leech JA, Chen SY, Burwash IG, Renaud J et al (2014) Effects of short-term continuous positive airway pressure on myocardial sympathetic nerve function and energetics in patients with heart failure and obstructive sleep apnea: A randomized study. Circulation 130:892-901. https://doi.org/10.1161/ CIRCULATIONAHA.113.005893

Publisher's Note Springer Nature remains neutral with regard to jurisdictional claims in published maps and institutional affiliations. 